\title{
Multicomponent supplement containing Chlorella decreases arterial stiffness in healthy young men
}

\author{
Takeshi Otsuki, ${ }^{1, *}$ Kazuhiro Shimizu, ${ }^{2}$ Motoyuki lemitsu ${ }^{3}$ and Ichiro Kono ${ }^{4}$ \\ 'Faculty of Sport and Health Sciences, Ryutsu Keizai University, 120 Ryugasaki, Ibaraki 301-8555, Japan \\ ${ }^{2}$ Sports Research \& Development Core, University of Tsukuba, 1-1-1 Tennodai, Tsukuba, Ibaraki 305-8577, Japan \\ ${ }^{3}$ Faculty of Sport and Health Science, Ritsumeikan University, 1-1-1 Noji-higashi, Kusatsu, Shiga 525-8577, Japan \\ ${ }^{4}$ University of Tsukuba, 1-1-1 Tennodai, Tsukuba, Ibaraki 305-8577, Japan
}

(Received 12 June, 2013; Accepted 10 July, 2013; Published online 3 October, 2013)

\begin{abstract}
Chlorella, a unicellular green alga, contains various antioxidants and other nutrients such as amino acids and fiber. Previous studies have reported that supplementation with multiple antioxidants reduces arterial stiffness, a well-established cardiovascular risk factor. We investigated the effects of Chlorella intake on arterial stiffness using a single-blinded, placebo-controlled crossover study design. Fourteen young men took placebo or Chlorella tablets for four weeks, with a 12-week washout period between trials, in a randomized order. Before and after each trial, blood pressure, heart rate, and brachial-ankle pulse wave velocity, an index of arterial stiffness, were measured. Treatment compliance was comparable between the two groups. There were no differences in blood pressure and heart rate before and after supplementation in both the placebo and Chlorella groups. Brachial-ankle pulse wave velocity decreased after Chlorella intake (before vs after intake; $11.6 \pm 0.2$ vs $11.1 \pm 0.1 \mathrm{~m} / \mathrm{s}, p=0.01$ ), but not after placebo intake (11.4 \pm 0.2 vs $11.4 \pm 0.2 \mathrm{~m} / \mathrm{s}, p=0.98)$. Multicomponent analysis of the Chlorella-containing tablet detected nutrients that can reduce arterial stiffness, such as antioxidant vitamins, arginine, potassium, calcium, and $n-3$ unsaturated fatty acids. These results suggest that intake of a Chlorella-containing multicomponent supplement can decrease arterial stiffness.
\end{abstract}

Key Words: antioxidants, arterial stiffness, Chlorella, multicomponent supplement

rterial stiffness is a well-established risk factor for cardio$A$ vascular disease. ${ }^{(1,2)}$ Previous studies have reported that some nutrients such as antioxidants, ${ }^{(3,4)}$ isoflavone, ${ }^{(5,6)} n-3$ unsaturated fatty acids, ${ }^{(7,8)}$ lactotripeptides, ${ }^{(9,10)}$ and potassium ${ }^{(11)}$ decrease arterial stiffness. However, interindividual differences in nutritional status may result in differences in the effects of various nutrients on arterial stiffness. Additionally, beneficial effects are more definitively seen when nutrients are taken in combination than in isolation. For example, combination treatment in men $(1 \mathrm{~g}$ vitamin $\mathrm{C}$ and $400 \mathrm{IU}$ vitamin $\mathrm{E}$ per day for 8 weeks) and the addition of antioxidants in women $(120 \mathrm{mg}$ vitamin $\mathrm{C}, 30 \mathrm{mg}$ vitamin E, $6 \mathrm{mg}$ beta-carotene, $100 \mu \mathrm{g}$ selenium, and $20 \mathrm{mg}$ zinc per day for 7.2 years) decreased aortic pulse wave velocity (PWV), ${ }^{(3,4)}$ an index of arterial stiffness, whereas supplementation with vitamin $\mathrm{C}$ alone in men (500 $\mathrm{mg}$ daily for 30 days) and vitamin $\mathrm{E}$ alone in women (400 IU daily for 10 weeks) did not decrease aortic PWV.(12,13) In this context, a multicomponent supplement suitable for individuals with different nutritional status is of significance.

The use of natural ingredients in a multicomponent supplement may be favorable, although it is not easy to determine the best nutritional composition of a dietary supplement. Chlorella is a unicellular green alga that grows in fresh water. Since it contains various antioxidants and other nutrients, Chlorella-containing multicomponent supplementation may help reduce arterial stiffness. However, the effect of Chlorella-containing supplements on arterial stiffness remains to be elucidated. We conducted a singleblinded crossover study to investigate effects of placebo and Chlorella supplementation on arterial stiffness. It is difficult to discriminate between reduced arterial stiffness and decreased blood pressure when both measures decrease simultaneously. Additionally, the menstrual cycle influences arterials stiffness. ${ }^{(14,15)}$ Hence, we recruited normotensive young men to investigate the effect of Chlorella intake on arterial stiffness without blood pressure and menstrual cycle changes as confounding factors.

\section{Materials and Methods}

Participants. Fourteen men volunteered to participate in this study; none of them use dietary supplements on a regular basis. There were four subjects who engaged in recreational exercise regularly (more than $30 \mathrm{~min} /$ day and 3 days/week) and two subjects who were kendo and futsal athletes (vigorous exercise 90$140 \mathrm{~min} /$ day and 5-6 days/week), respectively. The participants were asked not to modify their regular lifestyle while taking the tablets during the trial periods. None of the participants had any symptoms or history of overt chronic disease. None of the subjects were smokers or were taking any medication. The mean $\pm \mathrm{SE}$ age and height values were $20.2 \pm 0.3$ years and $1.67 \pm 0.01 \mathrm{~m}$, respectively.

The present study was approved by the Ethical Committee of the Institute of Health and Sport Sciences of the University of Tsukuba. This study conformed to the principles outlined in the Helsinki Declaration. All participants gave their written informed consent before their participation in this study.

Experimental design. Each participant took part in two supplement trials, placebo and Chlorella, in a randomized order. First, blood pressure and brachial-ankle PWV (baPWV), an index of arterial stiffness which has been widely used in Japan and other countries over the past 10 years, ${ }^{(16)}$ were measured as in our previous study. ${ }^{(17)}$ The following day, the participants were randomized into either the placebo or Chlorella (SunChlorella A; Sun Chlorella, Kyoto, Japan) group in a single-blinded manner, to be taken at a dose of 30 tablets per day ( 15 tablets twice daily, after breakfast and dinner) for four weeks. ${ }^{(18,19)}$ This is in accordance

*To whom correspondence should be addressed. E-mail: takeshi.otsuki17@gmail.com 
with the general recommended dosage for Japanese consumers. Second, blood pressure and baPWV measurements were taken one day after the final tablet intake. Compliance with the prescription was documented via intake logs. After a washout period of 12 weeks, the second trial commenced with the alternate group assignment.

Placebo and Chlorella tablets. The placebo and Chlorella tablets used in this study were the same as in our previous studies. ${ }^{(18,19)}$ The mass of each tablet was $243 \mathrm{mg}$ and $200 \mathrm{mg}$, respectively. The main components of the placebo tablet were lactose and colorant. The main ingredient of Chlorella tablet was dried Chlorella pyrenoidosa powder. The respective nutritional values per $100 \mathrm{~g}$ of the placebo and Chlorella tablets were: energy, 406 and $399 \mathrm{kcal}$; water, 3.2 and $5.3 \mathrm{~g}$; protein, 2.0 and $60.8 \mathrm{~g}$; lipids, 5.9 and $9.2 \mathrm{~g}$; sugar, 85.6 and $6.3 \mathrm{~g}$; dietary fiber, 1.1 and $11.9 \mathrm{~g}$; and ash, 2.2 and $6.5 \mathrm{~g}$. The color and shape of the placebo and Chlorella tablets were similar. Additional multicomponent analysis of the Chlorella-containing tablet was entrusted to the Japan Dairy Technical Association (Tokyo, Japan); the analyses were performed using high performance liquid chromatography, atomic absorption spectrophotometry, and other methods.

BaPWV and blood pressure. All subjects were asked to refrain from intense physical activity or exercise for a $24 \mathrm{~h}$ period prior to measurements, which were made after an overnight fast. After a resting period in a quiet, temperature-controlled room, baPWV was measured as in our previous studies. ${ }^{(17)}$ Briefly, brachial and post-tibial artery pressure waveforms were obtained simultaneously, in triplicate, by cuffs connected to an airplethysmographic sensor (form PWV/ABI; Omron Colin, Tokyo, Japan). The pulse-wave travel distance was calculated from the subject's height and the travel time was automatically determined from the waveforms. BaPWV was calculated as the travel distance divided by the travel time. In our laboratory, the representative day-to-day coefficient of variation for baPWV was $2.2 \pm 1.3 \%{ }^{(17)}$
Blood pressure was measured using oscillometry and heart rate (HR) was calculated from an electrocardiogram (form PWV/ABI, Omron Colin).

Statistical analysis. Results are given as means \pm SE. $P$ values of $<0.05$ were considered statistically significant. We tested whether the variables were normally distributed using the Kolmogorov-Smirnov test. Differences in patient compliance and change in baPWV between placebo and Chlorella trials were tested using $t$ tests. To compare the effects of Chlorella intake with placebo supplementation, a repeated-measures two-way (placebo or Chlorella $\times$ intake period) analysis of variance (ANOVA) was used. When a significant interaction was observed, one-way ANOVA and a post-hoc Bonferroni-Dunn test were used to identify the effects of placebo and Chlorella intake.

\section{Results}

All of the variables before and after intake were normally distributed in both groups. Compliance with the group assignment was comparable between the placebo and Chlorella groups $(97.3 \pm 1.0$ vs $96.7 \pm 1.2 \% ; t=0.5, p=0.65)$. There were no trial $x$ intake period interactions and no effects of group and intake were observed with respect to body weight (before vs after intake: placebo group, $65.6 \pm 2.2$ vs $66.3 \pm 2.2 \mathrm{~kg}$ and Chlorella group, $65.3 \pm 2.3$ vs $65.7 \pm 2.4 \mathrm{~kg} ; F=0.4$ and $p=0.50$ ), blood pressure, and HR (Table 1). There was a significant interaction in baPWV between group and intake period $(F=4.5, p=0.04$; Fig. 1A); baPWV decreased from baseline after Chlorella intake $(F=7.1$, $p=0.01)$ while placebo tablets had no effect $(F=0.0, p=0.98)$. The change in baPWV with a four-week trial was greater in the Chlorella group than in the placebo group (Fig. 1B). In the multicomponent analysis of the Chlorella-containing tablets, numerous nutrients were detected, some of which have been previously shown to lower arterial stiffness (Table 2).

Table 1. Blood pressure and heart rate before and after Chlorella intake

\begin{tabular}{lcccc}
\hline & & Before & After & Interaction \\
\hline Systolic blood pressure $(\mathrm{mmHg})$ & Placebo & $117 \pm 2$ & $118 \pm 2$ & $F=0.4$ \\
& Chlorella & $119 \pm 2$ & $119 \pm 2$ & $p=0.54$ \\
Diastolic blood pressure $(\mathrm{mmHg})$ & Placebo & $68 \pm 2$ & $68 \pm 2$ & $F=0.0$ \\
& Chlorella & $68 \pm 1$ & $67 \pm 1$ & $p=0.90$ \\
Heart rate (bpm) & Placebo & $59 \pm 2$ & $59 \pm 2$ & $F=0.1$ \\
& Chlorella & $59 \pm 2$ & $59 \pm 2$ & $p=0.77$ \\
\hline
\end{tabular}

Values are means $\pm \mathrm{SE}$
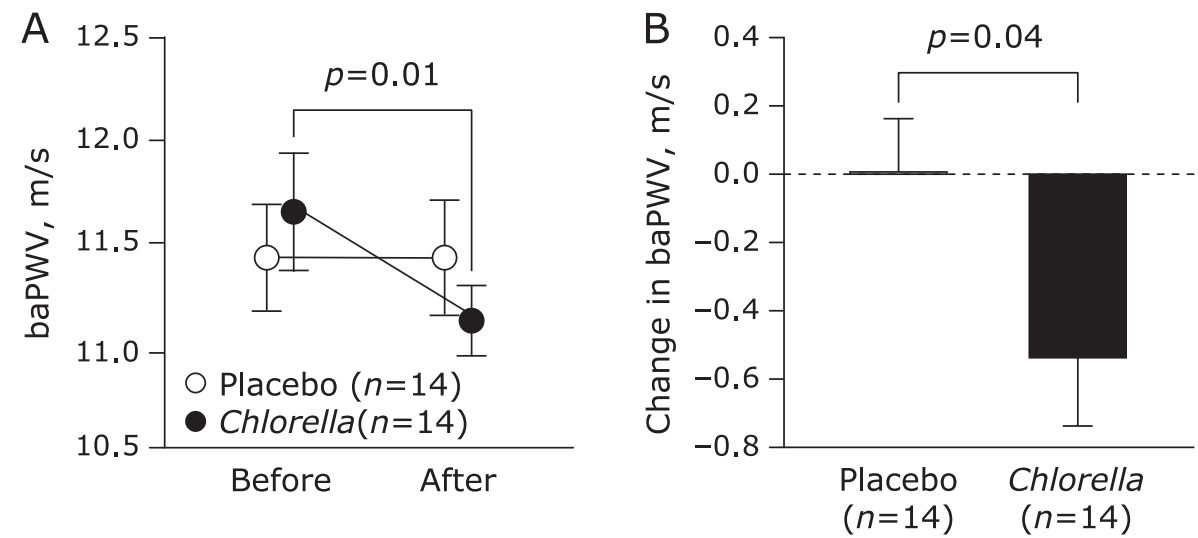

Fig. 1. Arterial stiffness before and after Chlorella intake. Values are means \pm SE. baPWV: brachial-ankle pulse wave velocity. 
Table 2. Primarily results of multicomponent analysis of Chlorella tablet

\begin{tabular}{|c|c|c|c|}
\hline \multicolumn{2}{|l|}{ Total } & \multicolumn{2}{|l|}{ Detail } \\
\hline Nutrient & Value & Nutrient & Value \\
\hline Protein $(\mathrm{g} / 100 \mathrm{~g})$ & 60.8 & Arginine $(\mathrm{g} / 100 \mathrm{~g})$ & 3.16 \\
\hline Carbohydrate $(\mathrm{g} / 100 \mathrm{~g})$ & 18.2 & Dietary fiber $(\mathrm{g} / 100 \mathrm{~g})$ & 11.9 \\
\hline Lipid (g/100 g) & 9.2 & $n-3$ unsaturated fatty acid (\%) & 8.6 \\
\hline \multirow[t]{7}{*}{ Ash $(\mathrm{g} / 100 \mathrm{~g})$} & 6.5 & Potassium (mg/100 g) & 970 \\
\hline & & Magnesium (mg/100 g) & 370 \\
\hline & & Calcium (mg/100 g) & 330 \\
\hline & & Beta-carotene $(\mathrm{mg} / 100 \mathrm{~g})$ & 4.3 \\
\hline & & Vitamin C (mg/100 g) & 4.0 \\
\hline & & Vitamin E (mg/100 g) & 2.7 \\
\hline & & Zinc $(\mathrm{mg} / 100 \mathrm{~g})$ & 1.1 \\
\hline
\end{tabular}

In the multicomponent analysis of the Chlorella-containing tablets, numerous nutrients were detected, some of which have been previously shown to lower arterial stiffness. A portion of this table is republished from our previous study. ${ }^{(18,19)}$

\section{Discussion}

This study investigated the effect of four weeks of a Chlorelladerived multicomponent supplement on baPWV using a singleblinded, randomized, crossover study design. The salient finding is that baPWV decreased from baseline after Chlorella supplementation, whereas no changes occurred when subjects took placebo. Additionally, many nutrients that can decrease arterial stiffness were detected in the multicomponent analysis of the Chlorella tablet. These results suggest that oral supplementation with a multicomponent supplement containing Chlorella decreases arterial stiffness.

Arterial stiffness and blood pressure affect each other; decreased blood pressure reduces arterial stiffness and vice versa. To investigate effects of lifestyle modification such as exercise on arterial stiffness in a blood pressure-independent manner, previous studies recruited normotensive individuals and demonstrated a decrease in arterial stiffness without blood pressure reduction. ${ }^{(17,20,21)}$ Similarly, there were no changes in blood pressure in both groups since we recruited normotensive individuals to rule out the effects of blood pressure on arterial stiffness. Additionally, women were not recruited to exclude the effects of the menstrual cycle on arterial stiffness. ${ }^{(14,15)}$ There were no smokers or subjects on medication in this study. These relative strengths of this study help isolate the effects of the Chlorella-containing tablets on arterial stiffness. Given the Bogalusa Heart Study's finding that carotid artery intima-media thickness is associated with the cumulative burden of cardiovascular risk factors starting in childhood, ${ }^{(22)}$ distensible central arteries would be preferable not only in older individuals but also younger individuals. However, it is unclear whether the present finding is applicable to older individuals and women. Further studies are warranted as next steps.

Arterial stiffness is determined by structural (e.g., elastin and collagen content in the arterial media) and functional (e.g., endothelial function and sympathetic nervous system activity) factors. However, more time is needed to elicit structural changes than functional changes. It is reasonable to assume that reductions in arterial stiffness during a four-week period were due more to functional changes. For instance, potassium can affect arterial stiffness by decreasing the contractility of vascular smooth muscle cells via sodium excretion. ${ }^{(23-25)}$ Arterial stiffness can be reduced by combined intake of antioxidant vitamins (i.e., vitamin $\mathrm{C}$ and $\mathrm{E}$ ) through improvements in vascular endothelial function. ${ }^{(3,26)} n-3$ Unsaturated fatty acids can improve arterial stiffness ${ }^{(7,8)}$ by the antiinflammatory function. ${ }^{(27)}$ In addition, arginine can be con- verted to nitric oxide, an endothelium-derived vasodilatory factor, which decreases arterial stiffness. ${ }^{(28,29)}$ However, it is unclear which mechanisms were responsible for the observed reduction in arterial stiffness in this study. A comprehensive investigation is necessary to determine the mechanisms responsible for the beneficial effects of Chlorella supplementation.

This study has several limitations. First, the subjects were normotensive young men as mentioned above. Additionally, the sample size was not large. Larger studies in older and hypertensive individuals are the next steps. Second, we could not investigate the mechanisms underlying the Chlorella-induced declines in arterial stiffness although we performed multicomponent analysis and discussed some possibilities. Third, this study could not control for the dietary habits of each subject that could influence the effects of Chlorella intake. For example, the effects may be less marked in individuals who are following diet restriction than counterparts because phosphate restriction improves endothelium function and sodium restriction reduces arterial stiffness. ${ }^{(30,31)}$ Finally, even though the dosage was in accordance with the current recommendations for consumers, the number of tablets taken per day was very high. A study to determine the optimal dosage is needed.

In conclusion, the present results suggest that intake of a Chlorella-containing multicomponent supplement decreases arterial stiffness in young normotensive men.

\section{Abbreviations}

ANOVA analysis of covariance

baPWV brachial-ankle pulse wave velocity

HR heart rate

PWV pulse wave velocity

\section{Conflict of Interest}

SunChlorella Co., Ltd. provided funding and the test supplements. TO has received a speaker's honorarium from SunChlorella Co., Ltd. KS, MI, and IK have no conflicts of interest. 


\section{References}

1 Vlachopoulos C, Aznaouridis K, Stefanadis C. Prediction of cardiovascular events and all-cause mortality with arterial stiffness: a systematic review and meta-analysis. J Am Coll Cardiol 2010; 55: 1318-1327.

2 Vlachopoulos C, Aznaouridis K, Terentes-Printzios D, Ioakeimidis N, Stefanadis C. Prediction of cardiovascular events and all-cause mortality with brachial-ankle elasticity index: a systematic review and meta-analysis. Hypertension 2012; 60: 556-562.

3 Plantinga Y, Ghiadoni L, Magagna A, et al. Supplementation with vitamins $\mathrm{C}$ and $\mathrm{E}$ improves arterial stiffness and endothelial function in essential hypertensive patients. Am J Hypertens 2007; 20: 392-397.

4 Zureik M, Galan P, Bertrais S, et al. Effects of long-term daily low-dose supplementation with antioxidant vitamins and minerals on structure and function of large arteries. Arterioscler Thromb Vasc Biol 2004; 24: 1485 1491.

5 Teede HJ, McGrath BP, DeSilva L, Cehun M, Fassoulakis A, Nestel PJ. Isoflavones reduce arterial stiffness: a placebo-controlled study in men and postmenopausal women. Arterioscler Thromb Vasc Biol 2003; 23: 10661071.

6 van der Schouw YT, Pijpe A, Lebrun CE, et al. Higher usual dietary intake of phytoestrogens is associated with lower aortic stiffness in postmenopausal women. Arterioscler Thromb Vasc Biol 2002; 22: 1316-1322.

7 Mita $\mathrm{T}$, Watada $\mathrm{H}$, Ogihara $\mathrm{T}$, et al. Eicosapentaenoic acid reduces the progression of carotid intima-media thickness in patients with type 2 diabetes. Atherosclerosis 2007; 191: 162-167.

8 Nestel PJ, Pomeroy SE, Sasahara T, et al. Arterial compliance in obese subjects is improved with dietary plant $n-3$ fatty acid from flaxseed oil despite increased LDL oxidizability. Arterioscler Thromb Vasc Biol 1997; 17: 11631170 .

9 Jauhiainen T, Rönnback M, Vapaatalo H, et al. Long-term intervention with Lactobacillus helveticus fermented milk reduces augmentation index in hypertensive subjects. Eur J Clin Nutr 2010; 64: 424-431.

10 Yoshizawa M, Maeda S, Miyaki A, et al. Additive beneficial effects of lactotripeptides and aerobic exercise on arterial compliance in postmenopausal women. Am J Physiol Heart Circ Physiol 2009; 297: H1899-H1903.

11 He FJ, Marciniak M, Carney C, et al. Effects of potassium chloride and potassium bicarbonate on endothelial function, cardiovascular risk factors, and bone turnover in mild hypertensives. Hypertension 2010; 55: 681-688.

12 Eskurza I, Monahan KD, Robinson JA, Seals DR. Ascorbic acid does not affect large elastic artery compliance or central blood pressure in young and older men. Am J Physiol Heart Circ Physiol 2004; 286: H1528-H1534.

13 Rasool AH, Rehman A, Wan Yusuf WN, Rahman AR. Vitamin E and its effect on arterial stiffness in postmenopausal women--a randomized controlled trial. Int J Clin Pharmacol Ther 2003; 41: 587-592.

14 Hayashi K, Miyachi M, Seno N, et al. Variations in carotid arterial compliance during the menstrual cycle in young women. Exp Physiol 2006; 91: 465472.

15 Williams MR, Westerman RA, Kingwell BA, et al. Variations in endothelial function and arterial compliance during the menstrual cycle. $J$ Clin Endocrinol Metab 2001; 86: 5389-5395.

16 Sugawara J, Hayashi K, Yokoi T, et al. Brachial-ankle pulse wave velocity: an index of central arterial stiffness? J Hum Hypertens 2005; 19: 401-406.

17 Otsuki T, Takanami Y, Aoi W, Kawai Y, Ichikawa H, Yoshikawa T. Arterial stiffness acutely decreases after whole-body vibration in humans. Acta Physiol (Oxf) 2008; 194: 189-194.

18 Otsuki T, Shimizu K, Iemitsu M, Kono I. Salivary secretory immunoglobulin A secretion increases after 4-weeks ingestion of chlorella-derived multicomponent supplement in humans: a randomized cross over study. Nutr $J$ 2011; 10: 91.

19 Otsuki T, Shimizu K, Iemitsu M, Kono I. Chlorella intake attenuates reduced salivary SIgA secretion in kendo training camp participants. Nutr J 2012; 11: 103.

20 Kakiyama T, Sugawara J, Murakami H, Maeda S, Kuno S, Matsuda M. Effects of short-term endurance training on aortic distensibility in young males. Med Sci Sports Exerc 2005; 37: 267-271.

21 Tanaka H, Dinenno FA, Monahan KD, Clevenger CM, DeSouza CA, Seals DR. Aging, habitual exercise, and dynamic arterial compliance. Circulation 2000; 102: 1270-1275.

22 Li S, Chen W, Srinivasan SR, et al. Childhood cardiovascular risk factors and carotid vascular changes in adulthood: the Bogalusa Heart Study. JAMA 2003; 290: 2271-2276.

23 Mano M, Sugawara A, Nara Y, et al. Potassium accelerates urinary sodium excretion during salt loading without stimulating atrial natriuretic polypeptide secretion. Clin Exp Pharmacol Physiol 1992; 19: 795-801.

24 Smith SJ, Markandu ND, Sagnella GA, Poston L, Hilton PJ, MacGregor GA. Does potassium lower blood pressure by increasing sodium excretion? A metabolic study in patients with mild to moderate essential hypertension. $J$ Hypertens Suppl 1983; 1: 27-30.

25 Voors AW, Dalferes ER, Jr, Frank GC, Aristimuno GG, Berenson GS Relation between ingested potassium and sodium balance in young Blacks and whites. Am J Clin Nutr 1983; 37: 583-594.

26 Engler MM, Engler MB, Malloy MJ, et al. Antioxidant vitamins C and E improve endothelial function in children with hyperlipidemia: Endothelial Assessment of Risk from Lipids in Youth (EARLY) Trial. Circulation 2003; 108: 1059-1063.

27 Khajehnasiri F, Mortazavi SB, Allameh A, Akhondzadeh S. Effect of omega3 and ascorbic acid on inflammation markers in depressed shift workers in Shahid Tondgoyan Oil Refinery, Iran: a randomized double-blind placebocontrolled study. J Clin Biochem Nutr 2013; 53: 36-40.

28 Hishikawa K, Nakaki T, Tsuda M, et al. Effect of systemic L-arginine administration on hemodynamics and nitric oxide release in man. Jpn Heart J 1992; 33: 41-48.

29 Nakaki T, Hishikawa K, Suzuki H, Saruta T, Kato R. L-arginine-induced hypotension. Lancet 1990; 336: 696.

30 Gates PE, Tanaka H, Hiatt WR, Seals DR. Dietary sodium restriction rapidly improves large elastic artery compliance in older adults with systolic hypertension. Hypertension 2004; 44: 35-41.

31 Van TV, Watari E, Taketani Y, et al. Dietary phosphate restriction ameliorates endothelial dysfunction in adenine-induced kidney disease rats. $J$ Clin Biochem Nutr 2012; 51: 27-32. 